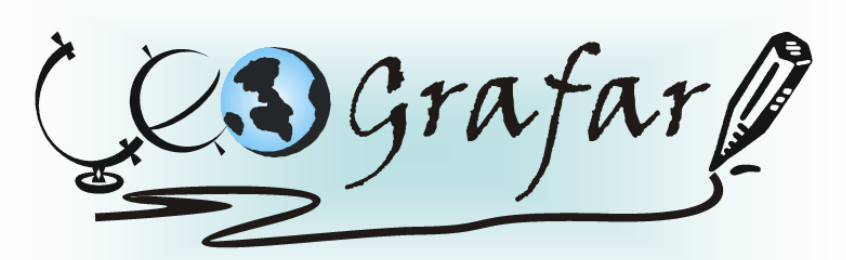

Revista Eletrônica do Programa de Pós-Graduação em Geografia - UFPR

\title{
A DINÂMICA POPULACIONAL NA REGIÃO DE IVAIPORÃ/PR (1970-2010)
}

\section{CLEITON COSTA DENEZ}

\begin{abstract}
RESUMO
O objetivo do presente trabalho é analisar a dinâmica populacional na região de Ivaiporã/PR. Assim, é discutida a mobilidade populacional entre os anos de 19702010, construindo uma análise a partir do processo de colonização que culminou com a ocupação regional e pelo processo de modernização agrícola que alterou a distribuição e organização da população local a partir de condicionantes externos. $O$ trabalhou se pautou em uma revisão bibliográfica básica sobre a colonização da região, da modernização agrícola e seus condicionantes e de dados do IBGE que evidenciam a evasão e alterações na distribuição da população local. Concluímos com a nossa leitura na região de Ivaiporã que os núcleos urbanos se formaram com a colonização da Sociedade Territorial Ubá (STUL), estabelecendo uma relação dialética entre rural e urbano em sua gênese. E ainda, sobre a política de modernização agrícola que condicionou o êxodo rural e 0 esvaziamento populacional. As mudanças empregadas pelo processo de modernização agrícola acarretaram em alterações nas relações locais, trazendo consequências econômicas, políticas e sociais.
\end{abstract}

Palavras-chave: Dinâmica, População, Colonização, Modernização, Ivaiporã.

\section{POPULATION DYAMICS IN IVAIPORÃ/ PR (1970-2010)}

\begin{abstract}
The present paper aims to analyze the population dynamics in Ivaiporã/PR. I discussed the population mobility between 1970 and 2010 and outlined an analysis of the colonization process that led to the settlement in the region. In addition, I investigated the agricultural modernization that modified the distribution and organization of the local population as from external constraints. This paper drew
\end{abstract}

1 Mestre em Geografia pela Universidade Estadual do Centro-Oeste - UNICENTRO. E-mail: cleiton.denez@hotmail.com 
from a basic review of literature on settlement, on the process of agricultural modernization and on data from IBGE. The analysis carried out in Ivaiporã demonstrated that the Sociedade Territorial Ubá (STUL) settlement formed its city centers, establishing a dialectical relationship between rural and urban in its genesis. Furthermore, I examined the agricultural modernization policies which conditioned the rural-urban migration and rural depopulation. The modifications applied in the process of agricultural modernization have caused changes in local relations, bringing economical, political and social consequences.

Key words: Dynamics, Population, Settlement, Modernization, Ivaiporã.

\section{INTRODUÇÃO}

A região em estudo está inserida na Mesorregião Norte Central Paranaense e respectivamente na Microrregião de Ivaiporã. Para estudo definimos como recorte espacial apenas os municípios colonizados pela Sociedade Territorial Ubá (STUL) a qual denominamos de região de Ivaiporã (Figura 01). A delimitação da área decorre do fato de que estes municípios sofrem influência e são polarizados pela cidade de Ivaiporã e foram colonizados pela STUL. Desta forma, traçamos uma regionalização especifica levando em conta critérios históricos e as semelhanças que há entre estes municípios. A regionalização do IBGE é utilizada apenas para localização da área, já que optamos por criar uma regionalização mais especifica. A região delimitada neste trabalho é composta por 08 municípios (Ivaiporã, Jardim Alegre, Arapuã, Ariranha do Ivaí, Godoy Moreira, São João do Ivaí, Lunardelli e Lidianópolis).

A nossa hipótese é que o espaço regional juntamente com sua dinâmica é condicionado pela mobilidade populacional, que no inicio foi desencadeada pelo processo de colonização e posteriormente alterada pela modernização agrícola. Assim, nosso objetivo é compreender a dinâmica populacional como condicionante da produção e reprodução do espaço regional. Para tanto recorremos a uma revisão bibliográfica sobre o processo de colonização, modernização agrícola e em dados do IBGE para compreensão da mobilidade populacional local. 
A região é formada por pequenos aglomerados urbanos, o maior segundo dados do IBGE de 2010, é Ivaiporã com 27.438 habitantes na área urbana, sendo base de sua economia o setor primário e terciário. O restante das cidades tem sua organização pautada na economia primária, onde a cidade acaba sendo extensão do modo de vida rural, ou o modo de vida urbano encravado em meio ao rural.

Os aglomerados urbanos e ampliação da área rural na região surgiram com o processo de colonização, que desenvolveu a ocupação regional de forma mais acelerada. A colonização e ocupação ocorreram mescladas com a violência pela disputa de terras na territorialização da STUL, empresa responsável pela comercialização de lotes rurais, contra os posseiros que também se encontravam na área. Tal situação se desdobrou com o domínio da STUL sobre a região comercializando pequenos lotes rurais juntamente com a comercialização de lotes urbanos por terceiros. Desta forma ocorreu a formação territorial das áreas rurais em contraste com os pequenos lotes urbanos que surgiram simultaneamente com a ocupação das terras.

Com o tempo esta área se moldou com o progresso econômico das lavouras de café que sustentavam as pequenas propriedades e mantinham os pequenos aglomerados urbanos da região. Esta situação sofreu alterações pela chegada do capital modernizado ao campo, alterando as relações de produção e toda a organização local em decorrência de um processo global chamado de "Revolução Verde".

Com a modernização agrícola, muitas pessoas deixaram o campo em direção às cidades para se dedicar às atividades assalariadas geralmente do segundo setor, por não se inserirem no novo modelo de produção no campo. A ação de um sistema desenvolvimentista não olhou para as peculiaridades presentes e levou a modernidade para a grande cidade com a tecnologia da industrialização e ao campo os maquinários e implementos. Porém, este mesmo sistema levou à exclusão no campo ao inserir o pequeno produtor neste modelo, e na cidade o inchaço urbano, que não conseguiu suprir as necessidades básicas de toda a população que chegava do campo, expulsas pela modernização agrícola causando o êxodo rural. 


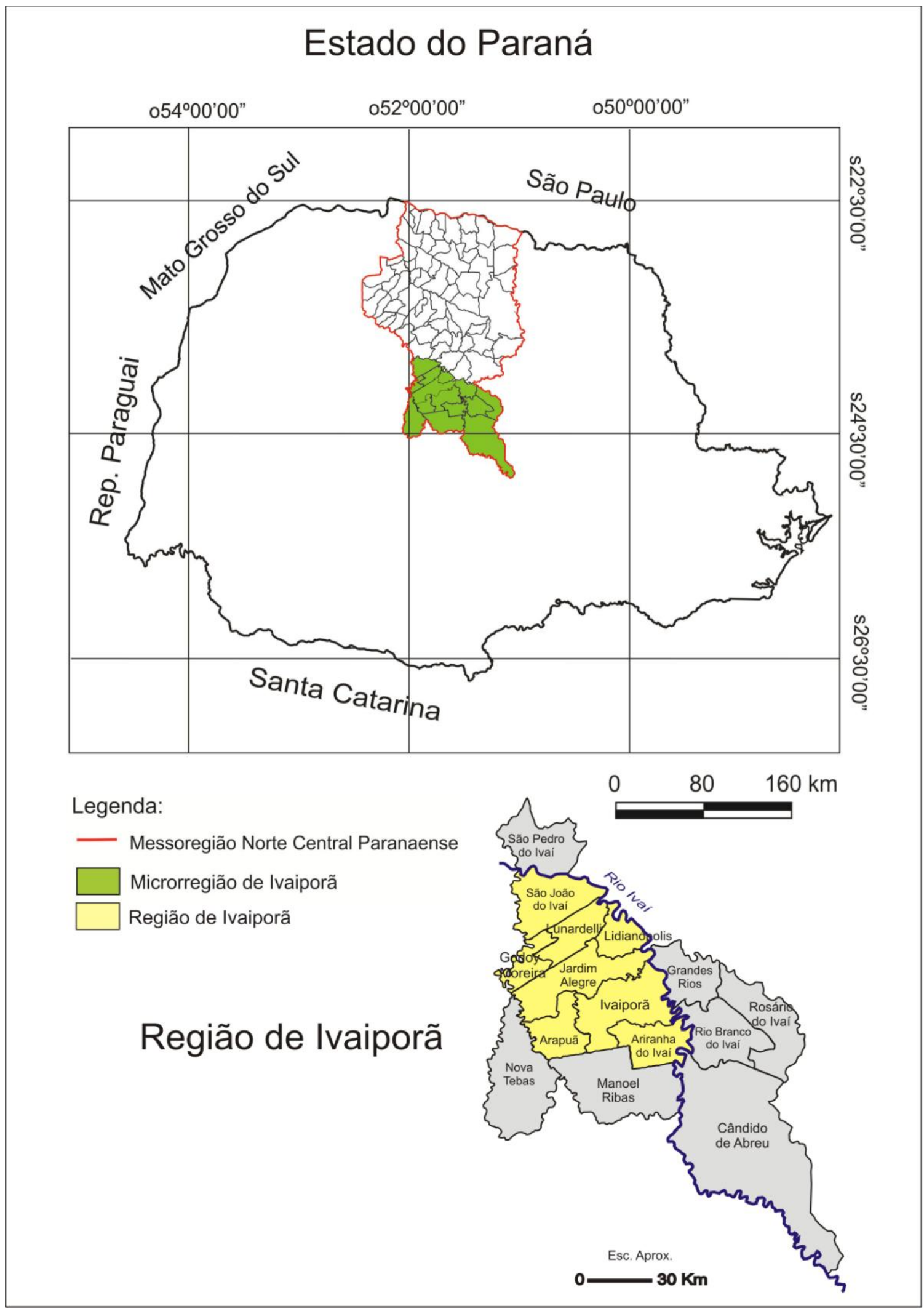

FIGURA 1 - LOCALIZAĈ̃O DA REGIÃO DE IVAIPORÃ FONTE: IBGE / ORGANIZADO PELO AUTOR (2011) 


\section{A COLONIZAÇÃO DA REGIÃO DE IVAIPORÃ}

Comecemos nossa análise pela colonização da região de Ivaiporã, que é justamente a área que definimos como recorte espacial, diferente da microrregião do IBGE por considerarmos somente os municípios que foram colonizados pela STUL.

O início da colonização da região de Ivaiporã ocorre em torno de 1939, quando os irmãos Barbosa Ferraz (Bráulio e Leogivildo), adquiriram um lote de Terras de aproximadamente 90.000 alqueires paulistas entre os rios Ivaí e Corumbataí, da então chamada Fazenda Ubá, para comercialização de lotes rurais. Porém, segundo Quiezi (1999) haviam irregularidades no título das terras da Ubá, sendo devolutas e apropriadas de forma imprópria.

Com a situação de irregularidade Estado do Paraná contestou a legitimidade das terras da Fazenda Ubá e as retomou. Com esta medida se iniciou o confronto entre o Governo do Paraná e os proprietários das terras da Ubá.

Em 1950 o Estado do Paraná desistiu de pleitear a posse e qualquer indenização das terras, havendo assim o entendimento amigável entre o Governo do Estado e os proprietários da Fazenda Ubá. No decorrer do litígio com o Governo do Paraná esse processo custou caro aos irmãos Barbosa Ferraz que para manter o processo buscou outros sócios, somando 37 sócios formando a Sociedade Territorial Ubá Ltda (STUL). Alguns foram remunerados em terras e o processo ainda originou novas empresas colonizadoras como a Sociedade Civil Agrícola Lunardelli Ltda.

O impasse entre os proprietários da Ubá e o governo do Estado gerou um clima de instabilidade na região. Como o Governo do Paraná considerou as terras devolutas e autorizava a entrada de posseiros na área os proprietários intimidavam os posseiros ameaçando-os de despejo. Os posseiros davam mais credibilidade no "papel" do Governo do Estado, pois estes recebiam o título de posse do Governo. Em 1948 Ludovico Mérico consegue junto ao Governo do Estado a autorização oficial para a vinda de colonos de Santa Catarina, quando vieram 200 famílias para a região. 
Como a STUL venceu a questão judicial, ganhou forças para promover a retirada dos posseiros de suas terras, o que vai gerar vários conflitos entre a STUL e os posseiros. Estes eram comunicados que ou comprariam as terras que já eram suas por direito de uso ou seriam expulsos, se não fosse cumprido o comunicado os "empregados" da STUL cumpriam a ordem de despejo, muitas vezes com o uso da força. Segundo Quiezi (1999) havia casos de empregados da STUL cortarem toda a plantação de milho para expulsar as pessoas e em outros casos matavam, torturavam e destruíam tudo o que possuíam.

A STUL utilizou um sistema de loteamento semelhante aos promovidos pela empresa colonizadora do norte do Paraná, a Companhia Melhoramentos Norte do Paraná (CMNP). A CMNP organizava a ocupação baseada em pequenas propriedades, com pequenos lotes onde se tornava fácil encontrar compradores utilizando várias formas de pagamento.

Quando mais colonos compravam e cultivavam terras aumentava a ocupação e gerava um comércio local desenvolvendo os núcleos urbanos e estimulando a venda de lotes urbanos. O loteamento organizado pela STUL era um negócio imobiliário, a ocupação através do trabalho valorizava as terras garantindo o lucro da Companhia. A STUL concedia uma série de facilidades de pagamentos, concedendo até quatro anos para pagamento parcelado, com o tamanho das propriedades em média de nove alqueires.

Com a estabilidade em relação à compra de terras da STUL após a regularização, várias pessoas vieram até a região e se fixaram no campo abrindo estradas e plantando as primeiras lavouras de café. A região se encheu com a produção cafeeira de agricultores em sua maioria vindos do Oeste-Paulista e Minas Gerais em propriedades de no máximo 09 alqueires em sua maioria.

A partir desta organização os aglomerados urbanos se encheram de vida diante da produção do café nas décadas de 1970 à 1980, as pequenas cidades se desenvolveram com a economia dinâmica movimentada pela comercialização e utilização de mão-de-obra da cultura cafeeira.

Entre estas décadas a economia urbana se moveu condicionada pela produção agrícola do café e a maioria das pessoas estava no campo que se deslocavam a cidade somente para comercializar o que foi produzido e comprar 
produtos básicos que era pagos no final de cada colheita ou para ir à igreja ou outras atividades sociais características de pequenas cidades.

Para comprar terras da STUL era necessário pagar $30 \%$ de seu valor e os 70\% restantes eram divididos em quatro anos. Quiezi (1999) ressalta que adquiridas ou negociadas com a STUL, as terras eram desbravadas, as madeiras usadas para construção das casas e as sobras vendidas para a serraria, ou simplesmente trocadas pela madeira já cortada. A região teve um grande aumento demográfico em 1960, conforme dados do IBGE que pode ser verificado na figura 02. Neste período a expansão da economia cafeeira trouxe várias pessoas em busca de crescimento econômico. A cultura cafeeira exigia o emprego de muita mão-de-obra, contribuindo para o aumento da população.

\footnotetext{
O café dos sítios passou a ser beneficiado ou nas grandes propriedades, quando o fazendeiro se dispunha dilatar seus rendimentos, beneficiando ou mesmo comercializando o café dos pequenos produtores, ou então, o beneficiamento passou a ser feito nos núcleos urbanos, emergentes no cenário cafeeiro, resultando no aparecimento de uma nova figura maquinista (CANCIAN, 1981, p. 77).
}

A pequena produção contribui para uma nova divisão do trabalho em que "os grandes proprietários diversificaram, ampliaram e expandiram suas atividades passaram a beneficiar e comercializar a produção de pequenos e médios "sítios"” (CANCIAN, 1981, p. 82). Assim, a divisão do trabalho, consistia na separação da produção do beneficiamento e comercialização do café. 


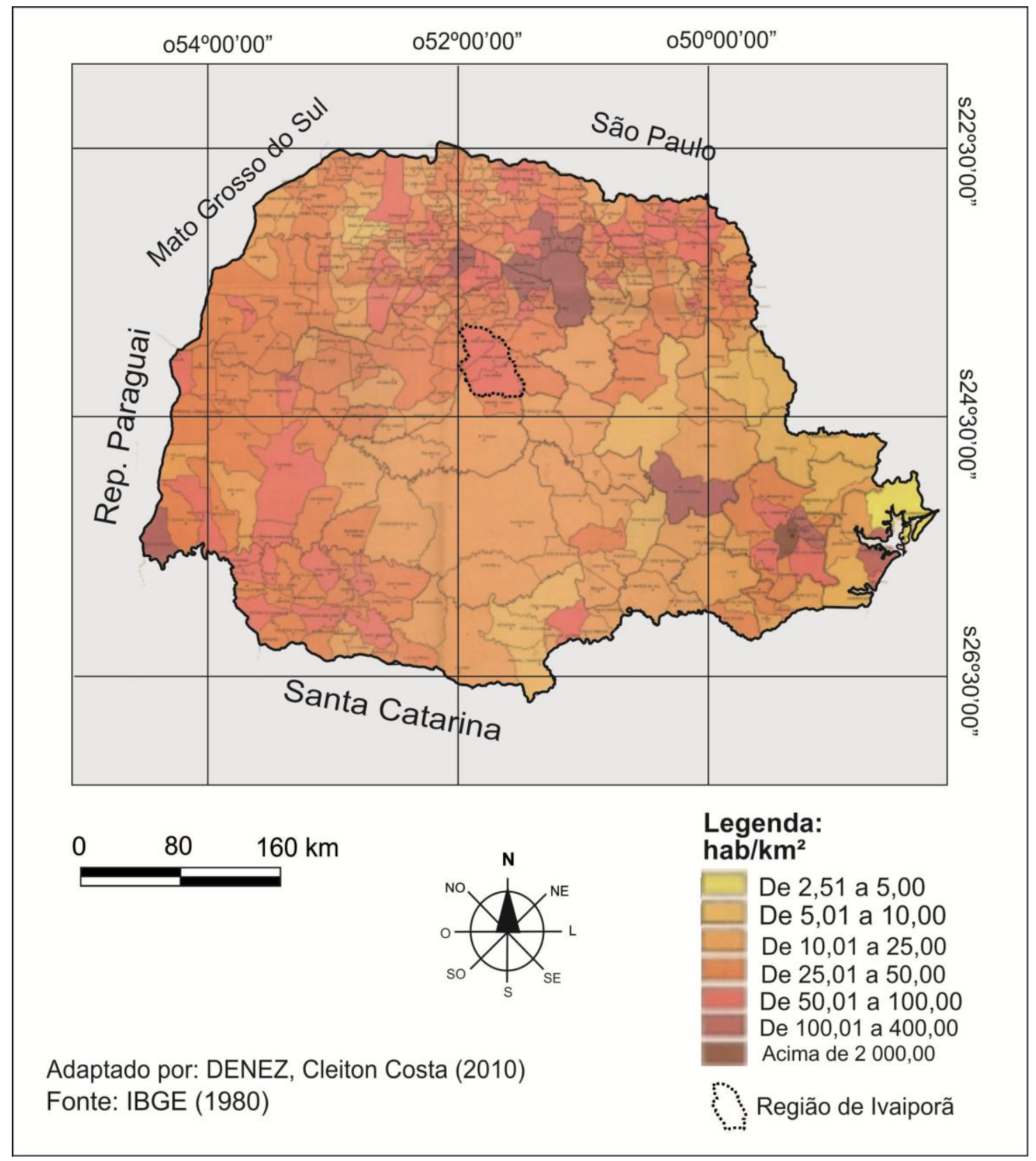

FIGURA 2 - DENSIDADE POPULACIONAL POR MUNICÍPIO DO PARANÁ EM 1980

Cancian (1981) destaca que onde está Ivaiporã, fica abaixo do paralelo 24ํㅡ, e que as condições ideais para a produção do café estavam acima deste, porém, a ânsia de lucros, dados aos preços e incentivadores pouco respeitou barreiras naturais. O território em estudo seguiu as tendências de colonização do Norte do Paraná se processando na sua terceira fase e sendo responsável para a sua ocupação. Desta maneira, a colonização e a ocupação se pautaram na 
cafeicultura e na diversificação das pequenas propriedades de mão-de-obra familiar. Este modelo propiciou a formação de pequenos aglomerados urbanos.

Mudanças externas de conjuntura internacional propiciaram 0 deslocamento de grandes empresas para os países subdesenvolvidos e alteraram a forma de ocupação e produção no campo. Atrelado ao processo de industrialização, estava o chamado processo de modernização agrícola, que condicionou mudanças na forma de cultivo do café na região norte do Paraná e a produção cafeeira. Com a cultura cafeeira, "entre 1940 e 1970, a população rural cresceu a altas taxas, apresentando um saldo migratório positivo de aproximadamente 2.800 mil habitantes” (FLEISCHFRESSER, 1988, p. 21). Com a modernização agrícola chegou a substituição de culturas, em terras mecanizadas como o milho, a soja e o trigo que necessitam de menor uso de mão-de-obra, contribuindo para a liberação da mão-de-obra do campo para os grandes centros urbanos provocando o êxodo rural. "Em apenas uma década, 1970-80, o saldo migratório foi negativo em cerca de 2.600 mil pessoas" (FLEISCHFRESSER, 1988, p. 21). A partir da modernização agrícola e a substituição de culturas, a dinâmica populacional da região se alterou e por consequência disso, alteraram-se as organizações politica, econômica e social da região.

\section{A MODERNIZAÇÃo AGRÍCOLA NA REGIÃO IVAIPORÃ}

A partir da década de 1980 começou a se alterar a organização da região em função do processo de modernização agrícola que alterou as relações locais em benefício de uma política voltada a uma agricultura modernizada com maquinários, insumos e tecnologia em nome de uma maior produtividade e do chamado progresso na agricultura.

Este processo, na região, foi fruto da política de modernização brasileira, que para Fleischfresser (1988) foi "excludente em relação a determinados tipos de produtores" e para Moro (1997) "conservadora e dolorosa":

Nas décadas de 1970 a 1980 surgiram grandes dificuldades na comercialização do café no exterior. O governo federal adotou uma política de incentivo à erradicação do café e a cultura cafeeira passou a ser ineficiente para a 
geração de divisas devido aos preços baixos do mercado externo e pelo excessivo cuidado requisitado por esta cultura e ainda as geadas das décadas de 1960 e 1970 que prejudicaram a produção.

A partir de 1970 a baixa na produção americana de soja abriu perspectivas no mercado internacional para a soja brasileira, com preços estimulantes para os produtores. Com estes novos fatores teve início a capitalização e a modernização da agricultura trazendo impactos para a estrutura social e para a rede urbana e a economia regional.

A substituição da cultura cafeeira por lavouras mecanizadas provocou um maciço êxodo demográfico no meio rural, o que afetou profundamente as cidades da região, cuja função primordial era o desembaraço da produção cafeeira e o abastecimento da população do seu espaço simbiótico.

Com o "fim" do café e a redução da população rural, as atividades econômicas e, conseqüentemente os mercados de trabalho desses pequenos núcleos urbanos sofreram retração, provocando o êxodo rural de seus habitantes para outras regiões do país ou para cidades maiores do próprio estado.

Com as políticas de crédito para modernização do campo, a pequena propriedade apresentava uma produção insuficiente, com isso seus proprietários foram estimulados a se desfazer de suas terras. Ocorre então a subordinação da pequena produção ao grande capital, que mal consegue garantir sua sobrevivência.

A implementação do conjunto de políticas que foi chamado de projeto de modernização conservadora da agricultura brasileira foi concebido pelo regime militar e produziu uma profunda alteração na estrutura socioeconômica paranaense.

Apesar das grandes propriedades monopolizarem a maior parte das áreas agrícolas do estado, a agricultura paranaense e da região antes de 1964 estava profundamente assentada na pequena produção.

Fleischfresser (1988) destaca que a partir da segunda metade dos anos setenta o Estado se mobilizou para implementação do projeto de modernização agrícola, o qual foi pautado em uma conjugação de interesses onde se destacam:

[...] o capital industrial nacional e internacional, interessados na ampliação do mercado interno para seus produtos; capitais urbanos interessados em 
diversificar seus investimentos; e segmentos da oligarquia rural preocupados com 0 fortalecimento de seus empreendimentos (FLEISCHFRESSER, 1988, p. 12).

Fleischfresser (1988) salienta que com essa conjugação de setores da classe dominante a reorganização do espaço rural brasileiro se processou de maneira conservadora e contribui para a expulsão de grande parte da população do campo como em Fernandes (1999):

\begin{abstract}
Essa política que ficou conhecida como modernização conservadora promoveu o crescimento econômico da agricultura, ao mesmo tempo que concentrou ainda mais a propriedade da terra, expropriando e expulsando mais de 30 milhões de pessoas que migraram para as cidades e para outras regiões brasileiras (FERNANDES. 1999, p. 39).
\end{abstract}

$\mathrm{Na}$ região em estudo, pode-se verificar o esvaziamento populacional a partir da década de 1970, que segundo dados do IBGE, chegou a 163.608 habitantes. A evasão é mais intensa após a década de 1980, com a população decaindo para a quantia de 149.183. Em 1996 a queda é ainda mais acentuada: a população vai para 93.783 e em 2007 para 76.744 e em 2010 para 73.799 conforme apresenta a figura 3. A partir dos dados apresentados se torna claro o esvaziamento populacional. 


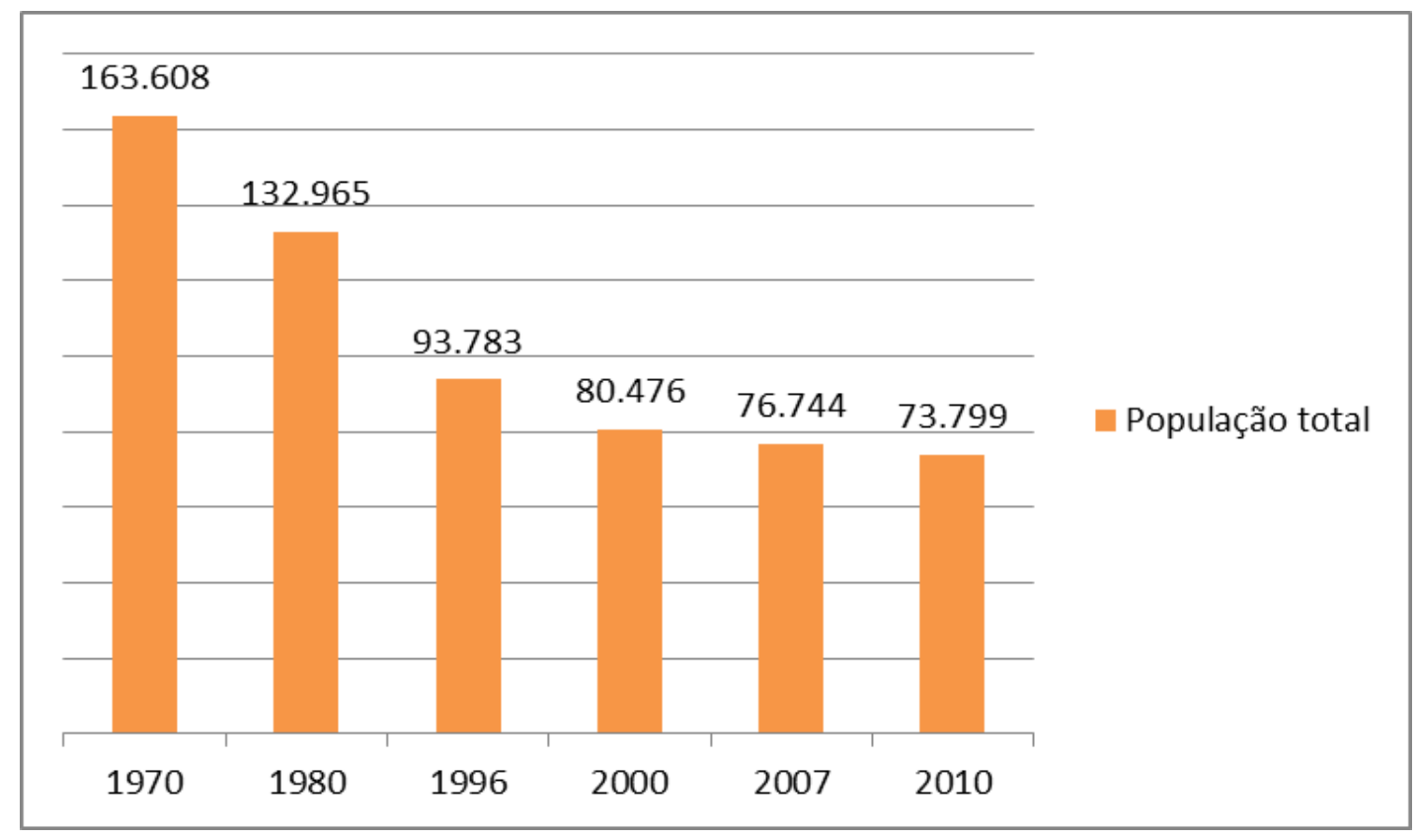

FIGURA 3 - NÚMERO TOTAL DA POPULAÇÃO NA REGIÃO DE IVAIPORÃ NOS ANOS DE 1970, 1980, 1996, 2007 E 2010.

FONTE: IBGE (1970, 1980, 1996 \& 2007)/ORGANIZADO PELO AUTOR (2011)

Os pequenos núcleos urbanos da região não apresentavam desenvolvimento tecnológico e nem um parque industrial que atendesse a população liberada do campo pelas mudanças condicionadas pela modernização agrícola. Passou a haver, assim, uma crescente emigração para núcleos urbanos maiores. Desta forma "a transformação tecnológica tendeu a homogeneizar a estrutura produtiva regional do Paraná, e concomitantemente a acentuar as diferenças econômicas e sociais entre os produtores" (FLEISCHFRESSER, 1988, p. 24). Para Fleishfresser (1988) ocorre uma "diferenciação sócio-econômica" com a modernização conservadora do campo. Esta modernização no caso da região, levou a tecnologia ao campo sem levar em conta o pequeno produtor e consequentemente os núcleos urbanos da região que eram dinamizados por eles.

O município de Ivaiporã perdeu grande parte de sua população com o êxodo rural e seria o único município que poderia receber parte da população que saiu do campo na região em direção aos grandes centros, porém, a cidade não conta com indústrias ou parque tecnológico para atender a demanda que emergia do campo e sua população também partiu em direção aos grandes centros. 
O esvaziamento populacional se apresentou de forma intensa na área rural, houve crescimento da população urbana na região, porém, se comparado com queda da população rural foi de pequena proporção. A partir da década de 1980 a queda da população rural foi intensa. O crescimento da população urbana se demonstrava de forma tímida, por ter a maior parte da população rural emigrado para outras áreas do estado e até do país. Por volta de 1990 a população urbana ultrapassou a rural, demonstrando o esvaziamento populacional do campo e da região, conforme se apresenta a figura 4.

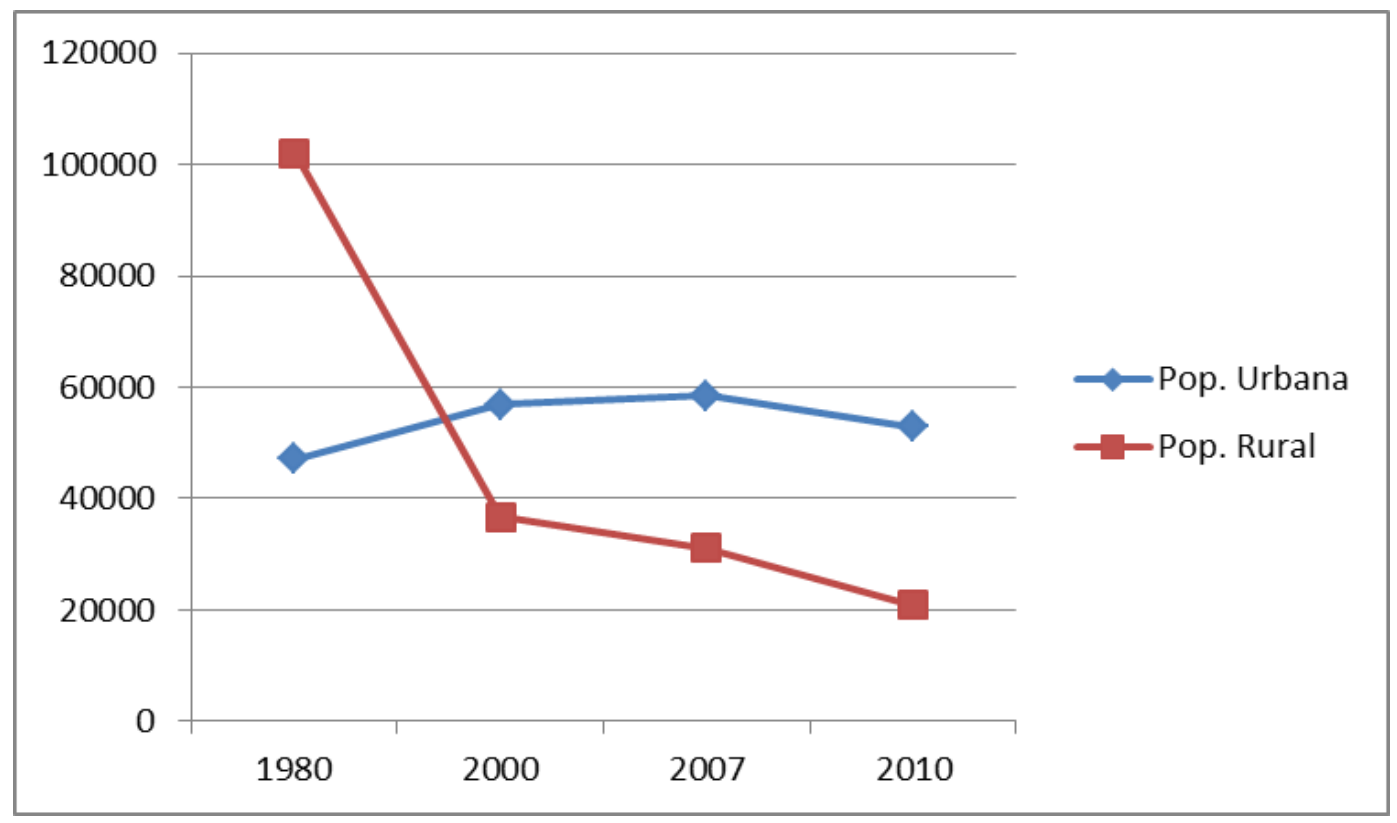

FIGURA 04: POPULAÇÃO RURAL E URBANA NA REGIÃO DE IVAIPORÃ, EM 1980, 2000, 2007 E 2010.

FONTE: IBGE (1980, 2000 \& 2007)/ORGANIZADO PELO AUTOR (2010)

Ivaiporã teve alguns distritos desmembrados que se tornaram municípios na década de 1990. Foram desmembrados Ariranha do Ivaí e Arapuã, com isto, parte da população de Ivaiporã passou a ser dos municípios recém-criados, assim, como aconteceu com Lidianópolis desmembrado de Jardim Alegre, Lunardelli e Godoy Moreira de São João do Ivaí. Ao analisar o esvaziamento populacional de Ivaiporã é possível verificar que houve uma perda de mais da metade da sua população, mesmo somado com os municípios recém-criados. Após 1990 Ivaiporã 
teria uma população de 37.829, sendo que em 1970 a sua população era de 67.988. Ivaiporã, segundo dados do IBGE, conta com uma população superior á 30.000 habitantes contando com o maior nível de urbanização do território, sendo 26.397 habitantes na área urbana para 4.947 na área rural. A população urbana de Ivaiporã ultrapassou a rural entre as décadas de 1980 e 1990.

Ivaiporã, no contexto das mudanças de organização da produção no campo, não possuía e ainda não possui a estrutura necessária para sustentar estas mudanças econômicas e ainda se encontra fora dos eixos rodoviários que compõem o principal anel viário do Paraná, distante dos principais pólos urbanos do estado. Nesta perspectiva, este município se tornou um centro periférico do Estado do Paraná, concentrando alguns serviços que polarizam os pequenos aglomerados urbanos da região. Com a maior população da região, apresenta um maior número de serviços para a população na área do comércio, saúde e educação. Nos serviços privados e públicos, Ivaiporã conta com uma infraestrutura que têm atendido os municípios vizinhos, onde inclusive se encontram as regionais do governo do Estado do Paraná.

Cabe aqui destacar um pouco sobre os municípios vizinhos, assim como já foi mencionado sobre Ivaiporã. Em Jardim Alegre conforme dados do IBGE, sofreu uma queda de 14.000 habitantes de 1970 para 1980 , confirmando o êxodo rural deste período. A modernização agrícola e a substituição de culturas entre os anos de 1980 para 1990 causou uma queda de 8.689 habitantes no município. Neste momento pode ser considerado o desmembramento de Lidianópolis. Porém, mesmo com Lidianópolis emancipado e com uma população de 4.912 habitantes, há uma queda de 3.777 habitantes, que deixaram ambos os municípios neste período. Jardim Alegre é único município da região que entre 1996 a 2007, contou com um aumento da população de 2.758 habitantes. Este fato se deve a ocupação da "Fazenda 7 Mil" pelo MST, atualmente o Assentamento 08 de Abril. Assentamento 08 de Abril contribuiu para o aumento populacional de Jardim Alegre e também por mudanças na dinâmica da economia dos municípios vizinhos. Jardim Alegre sofreu alterações não só econômicas com a presença do assentamento, mas de forma geral mudanças que alteram a dinâmica territorial e assim também política, econômica e social. 
Em relação aos municípios da região, cabe uma menção a São João do Ivaí, que também apresenta uma queda considerável de sua população, mesmo se levado em conta os desmembramentos de Lunardelli e Godoy Moreira, somando a população dos novos municípios de 1970 a 1980 houve uma queda de 6.623 habitantes.

Hoje o município de São João do Ivaí sofre grande influência da indústria de açúcar e álcool Vale do Ivaí S.A, que está territorializada em São Pedro do Ivaí, município ao norte, mas que tem influenciado e tornado os municípios próximos em canavieiros, neste sentido este município tem parte de sua dinâmica pautada no agronegócio.

São João do Ivaí apresenta uma alta população urbana, sendo 9000 habitantes na cidade para 2854 no campo, porém, suas atividades também estão vinculadas ao campo. Lunardelli conta com uma população urbana maior que a rural, 3.594 habitantes na área urbana para 1.566 rurais. Os municípios com maior extensão territorial contam com a maior população da região sendo que Jardim Alegre e São João do Ivaí contam com uma população maior que 10.000 habitantes.

De modo geral, ao avaliar-se a mobilidade demográfica da área territorial em estudo fica claro o esvaziamento populacional. Na década de 1970 e 1980 apresentava densidade populacional alta no estado (figura 02), sendo superada pelos grandes centros do estado como o eixo Londrina/Maringá, região Metropolitana de Curitiba, Ponta Grossa e Foz do Iguaçu.

Ao se averiguar o total da população rural e urbana é possível chegar à conclusão de que tem-se, na região de Ivaiporã, a população em sua maioria urbana, com 52.908 habitantes nas sedes municipais e distritos e 20.891 habitantes nas áreas rurais. Porém, ao fazer uma análise mais aprofundada destacando a situação de cada município é necessário ressaltar que até 2007, segundo dados do IBGE, haviam 4 municípios onde a maior parte da população, mesmo não sendo uma diferença expressiva, ainda se encontra no campo, entre estes está Arapuã, Ariranha do Ivaí, Godoy Moreira e Lidianópolis (TABELA 1). 
TABELA 1 - POPULAÇÃO URBANA E RURAL NA REGIÃO DE IVAIPORÃ EM 1980, 2000, 2007 E 2010

\begin{tabular}{|c|c|c|c|c|c|c|c|c|c|c|c|c|}
\hline Ano: & \multicolumn{3}{|c|}{1980} & \multicolumn{3}{|c|}{2000} & \multicolumn{3}{|c|}{2007} & \multicolumn{3}{|c|}{2010} \\
\hline Municípios & Urbana & Rural & Total & Urbana & Rural & Total & Urbana & Rural & Total & Urbana & Rural & Total \\
\hline Ivaiporã & 23.266 & 24.726 & 47.992 & 25.889 & 6.381 & 32.270 & 26.397 & 4.947 & 31.344 & 27.438 & 4.378 & 31.816 \\
\hline Arapuã* & 1.261 & 1.811 & 3.072 & 1.208 & 2.968 & 4.176 & 1.239 & 2.706 & 3.945 & 1.334 & 2.277 & 3.561 \\
\hline Jardim Alegre & 6.196 & 14.050 & 20.246 & 7.137 & 6.540 & 13.677 & 7.621 & 6.694 & 14.315 & 7.171 & 5.153 & 12.324 \\
\hline Lidianópolis* & 1.677 & 6.912 & 8.589 & 1.841 & 2.940 & 4.781 & 1.970 & 2.153 & 4.123 & 2.046 & 1.927 & 3.973 \\
\hline Lunardelli* $^{*}$ & 2.115 & 7754 & 9.869 & 2.701 & 2.963 & 5.664 & 3.435 & 1.647 & 5.082 & 3.594 & 1.566 & 5.160 \\
\hline $\begin{array}{l}\text { Total urbana e } \\
\text { rural: }\end{array}$ & 44.558 & 88.407 & 132.965 & 50.308 & 30.168 & 80.476 & 52.075 & 24.669 & 76.744 & 52.908 & 20.891 & 73.799 \\
\hline
\end{tabular}

FONTE - IBGE (1980, 2000, 2007 \& 2010) / ORGANIZADO PELO AUTOR (2011)

* Municípios criados após 1990 as informações anteriores divulgadas são como distrito. 
Os quatro municípios que possuíam a maior parte da população rural apresentam sua economia pautada na agricultura, já os municípios com a população maior que 10.000 habitantes possuem o terceiro setor da economia um pouco mais desenvolvido. Nos municípios menores as sedes abrigam pequenos comércios e prestação de serviços básicos para a população, quando necessários outros serviços a população se desloca para os municípios com mais de 10.000 habitantes que estão próximos ou para Ivaiporã. Grande parte da população urbana na maior parte do municípios estudados tem laços com o campo, sendo, pequenos proprietários rurais e em alguns casos fazendeiros que residem nas áreas urbanas, ou ainda, trabalhadores rurais temporárias, o chamado "boia-fria", que vem diminuindo cada fez mais devido à mecanização do campo.

Nos municípios que apresentam a maior parte da população na área rural as pessoas que não estão diretamente ligadas ao campo são pequenos comerciantes ou servidores públicos municipais. As prefeituras destes municípios contam com certo inchaço na folha de pagamento devido ao número elevado de funcionários.

A partir dos dados do IBGE do censo de 2010 apenas dois municípios não região ainda apresentam a maior parte de sua população na área rural, ainda pode ser destacado que a população rural continua em declínio devido a mecanização do campo. De acordo com observações em alguns municípios como o caso de Lidianópolis, grande parte da população tem deixado o município e procurado emprego no parque industrial de Arapongas no norte do estado do Paraná.

Os pequenos agricultores se vêm frustrados por não conseguirem se adaptar ao desenvolvimento capitalista e agregar valor e conseguir o esperado lucro em sua produção. Desta forma muito mais que para subsistência os trabalhadores rurais têm deixado o campo em busca dos sonhos de consumo e a oferta de uma vida melhor nos centros urbanos.

As pequenas cidades não têm oferecido atrações e grande parte dos serviços que os trabalhadores almejam para o crescimento econômico, uma delas é a formação acadêmica e profissional. A possibilidade de oferecer um futuro melhor para os filhos através da educação institucional, o único município que oferece 
formação superior é Ivaiporã e mesmo assim grandes partes dos jovens praticam a chamada migração pendular diariamente. Os que possuem famílias com poder aquisitivo maior se deslocam diariamente para Ivaiporã que é mais próximo ou para cidade como Pitanga, Apucarana, Jandaia do Sul, Mandaguari para se dedicar a um curso superior. Em outros casos há jovens que deixam as cidades temporariamente para residir em centros que possuem educação superior como Maringá, Londrina e Guarapuava.

A muitas situações que se apresentam para a queda da população na região, a modernização agrícola é logicamente a mais forte, porém, o modo de vida urbano com seus encantos não pode ser deixado de lado. É necessário lembrar também que não só os encantos, mas as necessidades que a população do interior requer. Como mencionada a situação do ensino superior que só tem sido oferecida por muitos anos na região por instituições particulares, sendo instalado campus da UEM em Ivaiporã apenas em 2010. O poder público tem se ausentado no atendimento da população do interior e isso tem causado o inchaço urbano nos grandes centros por parte da população que tem deixado o interior justamente por buscar serviços básicos e maior qualidade de vida.

A região em questão alterou sua dinâmica com a modernização agrícola que trouxe o desenvolvimento econômico para o campo, porém, não ocorreu o mesmo com os núcleos urbanos que não estavam preparados para receber a população oriunda do campo.

O processo de modernização agrícola alterou a dinâmica regional, bem como, sua produção e reprodução, que durante o processo de ocupação se pautava essencialmente na pequena propriedade pelo modelo de colonização da STUL, posteriormente pautado pela economia cafeeira. A colonização priorizava a comercialização de pequenos lotes rurais, naquele momento o conflito predominante foi entre posseiro e a STUL.

A territorialização do capital significa a desterritorialização do campesinato e
vice e versa. Evidente que esses processos não são lineares, tampouco
separados e contém a contradição porque na territorialização de um está
contida a produção e a reprodução de outro. No interior do processo de
territorialização do capital há a criação, destruição e recriação do trabalho
familiar. Da territorialização do campesinato produzem-se o trabalho
assalariado e o capitalista. Os avanços e recuos desses processos pelo 
território são determinados por um conjunto de fatores políticos e econômicos (FERNANDES, 1999, p. 270).

Fernandes (1999) considera que este contexto histórico, que atuou na produção territorial, ocorreu em um processo que acarreta em outros, como por exemplo, a territorialização da STUL representou a territorialização do capital e a desterritorialização do posseiro. A modernização agrícola trouxe a desterritorialização da produção de pré-capitalista da região, e todo este processo ocorreu por um conjunto de fatores políticos e econômicos que condicionaram estas mudanças.

Esta discussão, de forma geral, apresenta o que as políticas de modernização agrícola ocasionaram na região, a qual foi palco de relações de poder entre diferentes atores, como o poder municipal, privado e social e ainda outros que se fizeram presentes nesta relação pelos vários processos que foram desencadeados na região.

Com a chegada da política de modernização no campo, a pequena produção foi sendo apropriada pela produção comercial e a expansão capitalista se produz a partir da expropriação do pequeno proprietário que tem deixado a área em direção aos grandes centros. Para Fleischfresser (1988), este processo atingiu principalmente os produtores com unidades de até 20 hectares, predominantes na região. E assim, com a modernização agrícola houve o êxodo rural e a concentração fundiária no local.

A região se tornou área estagnada com a modernização agrícola que trouxe o desenvolvimento técnico para o campo, porém, não ocorreu o mesmo com os núcleos urbanos regionais que não estavam preparados para receber a população que saía do campo. É momento de se pensar em políticas públicas que levem em conta a interiorização de algumas necessidades para que se controle o esvaziamento populacional de regiões deprimidas, de modo que se pense na qualidade de vida destas populações. 


\section{CONSIDERAÇÕES FINAIS}

A dinâmica entre os espaços rurais e urbanos abordada na região em estudo se dá principalmente por fatores econômicos. Entre estes podem ser citados os que motivaram a ocupação com o processo de colonização pela STUL que gerou conflitos no campo pela disputa de terras. Com a colonização se formaram os núcleos urbanos da região juntamente com a estrutura que ligava estes com os principais pólos urbanos do Estado. Os aglomerados urbanos se desenvolveram principalmente pela atividade agrícola cafeeira que movia a região com as pequenas propriedades e pela intensa mão-de-obra que essa cultura utilizava.

Com a Modernização agrícola a dinâmica do espaço regional deixou de ser apenas local e passou a ser condicionada pelas políticas nacionais de desenvolvimento agrícola que almejava a modernização do campo, que ocorreu de forma conservadora. A modernização trouxe consequências sociais, políticas e econômicas como o êxodo rural. Grande parte da população rural ao deixar o campo em direção das cidades grandes alterou a dinâmica local e a estagnação econômica emergiu com as questões sociais tanto nos espaços rurais como urbanos.

Nossa tentativa foi de construir uma reflexão em tono da mobilidade populacional na região de Ivaiporã com as conjunturas que se estabeleceram ao longo do tempo. Tais conjunturas envolvem a colonização que dirigiu a ocupação e assim a mobilidade populacional na região e o processo de modernização que alterou as relações locais, empreendida pelo Estado e pelos setores dominantes do mercado. 


\section{REFERÊNCIAS}

BRASIL - Instituto Brasileiro de Geografia e Estatísticas (IBGE). Sinopse preliminar do Censo demográfico: Paraná. Rio de Janeiro. 1981.

BRASIL - Instituto Brasileiro de Geografia e Estatísticas (IBGE). Sinopse preliminar do Censo agropecuário: Paraná. Rio de Janeiro. 1982.

BRASIL - Instituto Brasileiro de Geografia e Estatísticas (IBGE): "Contagem populacional do Paraná"; IBGE, 2007; acessado em: http://www.ibge.gov.br/home/estatistica/populacao/contagem2007/PR.pdf.

BRASIL - Instituto Brasileiro de Geografia e Estatísticas (IBGE): cidades. Acessado em 18/06/2011. Disponível em: http://www.ibge.gov.br/cidadesat/link.php?codmun=411250

CANCIAN, Nadir Apparecida. Cafeicultura paranaense: 1900/1970. Curitiba: Grafipar, 1981.

FERNANDES, Bernardo Mançano. Contribuição ao Estudo do Campesinato Brasileiro: formação e territorialização do Movimento dos Trabalhadores Rurais Sem Terra - MST (1979 -1999). Tese (Doutorado em Geografia) Faculdade de Filosofia, Letras e Ciências Humanas, Universidade de São Paulo, 1999.

FLEISCHFRESSER. Vanessa. Modernização Tecnológica da Agricultura: contrastes regionais e diferenciação social no Paraná da década de 70. Curitiba: Livraria do Chain: CONCITEC: IPARDES, 1988.

MORO, Dalton Áureo. Desenvolvimento Econômico e Dinâmico Espacial da População no Paraná Contemporâneo. Relatório Final: subprojeto do projeto de pesquisa integrado: Paraná Urbano: Raízes, processos e problemas do Departamento de Geociências da Universidade Estadual de Londrina. 1997.

MORO, Dalton Áureo. Substituição de Culturas, Modernização Agrícola e Organização do Espaço rural, no Norte do Paraná. Tese de Doutoramento apresentada ao Instituto de Geociências e Ciências Exata da Universidade Estadual Paulista (UNESP) "Julio de Mesquita Filho". Rio Claro - SP. 1992, 353 p.

QUIEZI, Simone Aparecida - Companhia Ubá: Colonização e Ocupação do Território entre os Rios Ivaí e Corumbataí (1939-1970). Monografia apresentada como requisito de especialização em história à FAFIMAM. Mandaguari, 1999.

(Recebido em 25.07.2011. Aceito em 19.10.2011) 